\section{Has the Bill and Melinda Gates Foundation had a negative impact on global health?}

Published online first on August 3, 2021. DOI: 10.20529/IJME. 2021.058

Is the lack of action by the World Health Organization (WHO) against the growing global obesity and diabetes epidemics influenced by the Bill and Melinda Gates Foundation's pharmaceutical investments and knowledge creation? Diabetes Type-2 is increasing globally and is a serious health risk. According to Dain

Diabetes is a devastating condition, which alongside cancer, cardiovascular diseases, chronic respiratory diseases, and mental and neurological conditions, has long been side-lined by politicians and policymakers. (1)

March 3rd was World Obesity Day. The following report came out on that day: "COVID-19 and Obesity: The 2021 Atlas The cost of not addressing the global obesity crisis" (2). The report summarises the strong evidence for the relationship between obesity levels and Covid-19 death rates. It calls on governments to include people living with obesity among the groups prioritised for testing and vaccination, and to urgently tackle obesity to reduce the risks of serious symptoms and death (2).

Considering that diabetes and obesity are strongly associated with Covid-19 severity and mortality (3), why are the WHO and national public health departments not addressing the global obesity problem? People need to be aware that Type-2 diabetes can be reversed with improved eating habits (4). Why is Bill Gates not giving presentations to educate the public on reversing Type-2-diabetes?

It has been known since the first wave in March 2020 that people who are overweight especially suffer serious Covid-19 infections. Improving metabolic health can prevent serious respiratory virus infections: "being overweight not only increases the risk of infection and of complications for the single obese person, but a large prevalence of obese individuals within the population might increase the chance of appearance of more virulent viral strains, prolongs the virus shedding throughout the total population and eventually might increase overall mortality rate of an influenza pandemic." (5)

Future pandemics are more likely since obesity is growing all over the globe. These outbreaks are likely to lead to a greater need for emergency measures, and a greater push towards immunity certificates and masking and mandatory vaccines.

Has the WHO's vaccine focus increased since Bill Gate's nongovernmental organisation, GAVI, became involved in the campaign in 2009 ?

GAVI gained nation status amongst countries connected with the WHO when it was recognised as an "international institution"-"the first organisation to receive such recognition under the new Swiss Host State Act." (6). As such, GAVI qualified for diplomatic immunity, while not paying tax. Due to "governmental" immunity, GAVI's influence cannot be legally scrutinised.

Apart from its influence within the $\mathrm{WHO}$, the Bill and Melinda Gates Foundation is funding specific quantitative metrics in academic research. In particular, the Institute for Health Metrics and Evaluation (IHME), which is creating a kind of monopoly on knowledge production. This has resulted in a decline of the WHO's autonomy, financing, and credibility (7).

Furthermore, according to The Nation's analysis of the Foundation's most recent tax returns, its website, and various SEC filings, the Bill and Melinda Gates Foundation reports having investments in companies working on Covid vaccines, therapeutics, diagnostics and manufacturing (8).

A recent article funded by the Bill and Melinda Gates Foundation on strategies to prevent future pandemics discusses making vaccination and masks and social distancing mandatory, but neglects to address metabolic health (5). This again reveals neglect of the metabolic risk factors to develop serious Covid-19 infections, in favour of a vaccine focus and infection prevention measures (9).

During GAVI's participation, the WHO has changed the definition relating to infection mortality and the pandemic definition. These altered definitions can trigger emergency declarations. Now the only requirement to call an outbreak a "pandemic' is a worldwide disease. Influenza can now trigger emergency measures: "Simultaneous worldwide transmission of influenza is sufficient to define an influenza pandemic." (10)

Furthermore, the WHO definition for immunity is now connected with having had the vaccine rather than past infection: "WHO supports achieving 'herd immunity' through vaccination" (11).

Is the WHO's main focus on vaccines misplaced when a large part of Covid-19 morbidity and mortality is due to nutritional status? "Of the 2.5 million COVID-19 deaths reported by the end of February 2021, 2.2 million were in countries where more than half the population is classified as overweight." (2)

Has GAVI's influence within the WHO and its focus on vaccines become too strong, supported by the Foundation's funding to collect specific data; and has that resulted in sidelining non-communicable diseases like obesity and Type-2diabetes, which will have a negative impact on improving global health?

Conflicts of interest: No financial conflict of interest to declare.

Non-financial conflict of interest: During my career I have expressed my concerns about the increase in vaccines, see 
Pubmed and BMJ Rapid responses:

https://pubmed.ncbi.nlm.nih.gov/?term=havinga+w

https://www.bmj.com/search/wouter\%20AND\%20vaccine? f\%5B0\%5D=bundle\%3Ahighwire_comment\&solrsort=created\% 20desc

Wouter Havinga (wouter.havinga@gmail.com), Retired Family Doctor, Stroud, GL6 6JL, UK.

\section{References}

1. Dain K. Data-driven policies needed to turn the tide on diabetes. Lancet. 2020 Dec 19[cited 2021 Mar 24]; 396(10267):1948-9.

2. World Obesity Federation. COVID-19 and Obesity: The 2021 Atlas. London: World Obesity Federation; 2021 Mar [cited 2021 Mar 24]. Available from: https://www.worldobesityday.org/assets/downloads/ COVID-19-and-Obesity-The-2021-Atlas.pdf

3. Cefalu WT, Rodgers GP. COVID-19 and metabolic diseases: a heightened awareness of health inequities and a renewed focus for research priorities. Cell Metabolism. 2021 Feb 8 [cited 2021 Aug 1]. Available from: https://www.cell.com/cell-metabolism/fulltext/S15504131(21)00062

4. Taylor R, Ramachandran A, Yancy WS, Forouhi NG. Nutritional basis of type 2 diabetes remission. BMJ. 2021 Jul 7[cited 2021 Aug 1];374: n1449. Doi: https://www.bmj.com/content/374/bmj.n1449
5. Luzi L, Radaelli MG. Influenza and obesity: its odd relationship and the lessons for COVID-19 pandemic. Acta Diabetol. 2020 Jun [cited 2021 Mar 24];57(6):759-64. Available from: https://link.springer.com/ article/10.1007/s00592-020-01522-8.

6. GAVI. Gavi recognised as international institution. GAVI website. 2009 Jun 23[cited 2021 Mar 24]. Available from: https:// www.gavi.org/gavi-recognised-as-international-institution

7. Mahajan M. The IHME in the shifting landscape of global health metrics. Global Policy. 2019 Jan [cited 2021 Mar 24];10(Suppl 1): 11020. Available from: https://onlinelibrary.wiley.com/doi/epdf/ 10.1111/1758-5899.12605

8. Schwab T. While the Poor Get Sick, Bill Gates Just Gets Richer. The Nation. 2020 Oct 5[cited 2021 Mar 24]. Available from: https:// www.thenation.com/article/economy/bill-gates-investments-covid

9. Murray CJ, Piot P. The Potential Future of the COVID-19 Pandemic: Will SARS-CoV-2 Become a Recurrent Seasonal Infection? JAMA. 2021 Mar 3[cited 2021 Mar 24]. Available from: https:// jamanetwork.com/journals/jama/fullarticle/2777343

10. Kelly $\mathrm{H}$. The classical definition of a pandemic is not elusive. Bull World Health Organ. 2011[cited 2021 Aug 1];89(7):540-1. Doi: 10.2471/BLT.11.088815 Available from: https:// www.ncbi.nlm.nih.gov/pmc/articles/PMC3127276/

11. World Health Organization. Coronavirus disease (COVID-19): Herd immunity, lockdowns and COVID-19. Geneva: WHO; 2020 Dec 31[cited 2021 Mar 24]. Available from: https://www.who.int/newsroom/q-a-detail/herd-immunity-lockdowns-and-covid-19

\section{Advertise with us}

IJME welcomes advertisements for the print issue as well as the website. The guidelines, tariff details, and payment details are available at https://ijme.in/advertise/. The advertisement spaces for the website are available on the landing page and can be viewed at https://ijme.in/ . The advertisement rates are given below.

\section{For print:}

\begin{tabular}{|l|c|c|r|r|}
\hline \multicolumn{1}{|c|}{ Colour scheme } & Type & Dimension (cm) & \multicolumn{2}{c|}{ Rates (in INR) } \\
\hline & & & Single issue & Four issues \\
\hline Black and white & Full page & 24 height x 18 width & 25000 & 85000 \\
\hline Black and white & Half page & 12 height x 18 width & 15000 & 50000 \\
\hline Black and white & Quarter page & 10 height x 8.8 width & 6500 & 25000 \\
\hline Colour cover - inside/outside & Full page & 24 height x 18 width & 40000 & 125000 \\
\hline
\end{tabular}

Format of the images: High resolution; jpeg/png/gif/tiff

Single issue: quarter; four issues: whole year.

\section{For website:}

\begin{tabular}{|c|c|c|r|r|r|}
\hline Type & Dimension (pixels) & Placement & \multicolumn{2}{|c|}{ Rates (in INR) } \\
\hline & & & $\begin{array}{c}\text { One month } \\
\text { (30 days) }\end{array}$ & One quarter & One year \\
\hline Banner & 60 height x 832 width & $\begin{array}{c}\text { Landscape view in between the } \\
\text { homepage }\end{array}$ & 20000 & 50000 & 200000 \\
\hline Box & 165 height x 257 width* & Top right, below the navigation bar & 20000 & 50000 & 200000 \\
\hline
\end{tabular}

You can write to us at fmesmumbai@gmail.com or ijmemumbai@gmail.com for placing of advertisements and for any queries. 